\title{
Variantes de escape del virus de la hepatitis B
}

\author{
Carlos Mario Jaramillo y María-Cristina Navas
}

\author{
Facultad de Medicina, \\ Universidad de Antioquia, \\ Medellín, Colombia. \\ Grupo de Gastrohepatología (CM, \\ $\mathrm{M}-\mathrm{CN})$ \\ Los autores declaran no tene \\ conflicto de intereses. \\ Fuente de financiamiento: \\ Departamento Nacional de Ciencia, \\ Innovación y Tecnología, Colciencias \\ (110151929040) y Estrategia para \\ la sostenibilidad, Vicerrectoría \\ de Investigación, Universidad de \\ Antioquia. \\ Recibido: 4 de agosto de 2014 \\ Aceptado: 26 de febrero de 2015 \\ Correspondencia a: \\ María-Cristina Navas \\ maria.navas@udea.edu.co
}

\section{Introducción}

L a infección por el virus de la hepatitis B (VHB) es un problema de salud pública mundial; se estima que alrededor de dos billones de individuos han sido infectados por este virus y de éstos, 350 millones presentan infección crónica ${ }^{1,2}$. Las regiones de alta prevalencia para infección por el VHB se ubican en África sub-sahariana, el sudeste de Asia y en América, la cuenca amazónica compartida por Brasil, Perú, Venezuela, Ecuador y Colombia ${ }^{2-4}$.

Debido al tamaño de la población que ha sido infectada por el VHB y a las pérdidas económicas que causa esta infección, se han implementado políticas y medidas para el control, principalmente en regiones donde la infección por el VHB es endémica y las tasas de infección vertical y horizontal son altas. Una de esas medidas de control ha sido el desarrollo de una vacuna recombinante $e^{2,3}$.

La vacuna recombinante contra el VHB ha sido implementada principalmente en las regiones con alta endemia para la infección contra este virus. El $92 \%$ de los países en el mundo han implementado esta vacuna con una cobertura global de $69 \%$. Los anticuerpos producidos en respuesta a la vacuna están dirigidos contra el determinante "a" del HBsAg. Sin embargo, se han caracterizado aislados de VHB con mutaciones en la región del determinante "a"; estas mutaciones son denominadas variantes de escape porque impiden su reconocimiento por los anticuerpos neutralizantes anti-HBs, desarrollados en respuesta a la vacuna o a la infección natural. La circulación de variantes de escape del VHB tiene importantes implicaciones para la salud pública ${ }^{2,5-7}$.

\section{Genoma viral}

El virus de la hepatitis B (VHB) está clasificado en la familia Hepadnaviridae, género Orthohepadnavirus. El VHB posee un genoma circular de doble cadena parcial, de aproximadamente $3,2 \mathrm{~Kb}$. El genoma tiene cuatro marcos de lectura abierta (ORFs) superpuestos que dan origen a las siete proteínas virales: ORF P que codifica la polimerasa, ORF C que codifica la proteína core $(\mathrm{HBcAg})$ y el antígeno $e$ ( $\mathrm{HBe} A g)$, ORF X que codifica la proteína HBx y ORF $S$ que codifica las tres formas del antígeno de superficie (HBsAg) (Figura 1) . $^{8}$

La polimerasa del VHB presenta actividad de transcripción reversa, de ADN polimerasa y de ARNasa H; sin embargo, no posee actividad exonucleasa $3^{\prime}-5^{`}$ y por lo tanto no corrige los errores en la secuencia generados durante el proceso de retro-transcripción y de síntesis de la cadena positiva del genoma viral. La tasa de mutaciones del VHB es de 2,3 x $10^{-5}$ sitios/año 9 . Mutaciones en la secuencia que codifica el determinante "a" del HBsAg se denominan variantes de escape; estas mutaciones son importantes epidemiológicamente porque a pesar de que su prevalencia es baja, pueden ser seleccionadas y diseminarse causando así infección en individuos vacunados $^{7,10-11}$.

\section{Genotipos y serotipos de VHB}

Cuatro serotipos han sido designados para el VHB denominados $a d w, a y w, a d r$ y $a y r$, los cuales se dividen en 10 serotipos menores, ayw1, ayw2, ayw3, ayw4, ayr, adw2, $a d w 3, a d w 4 q-, a d r$ y $a d r q-$; la primera letra corresponde 


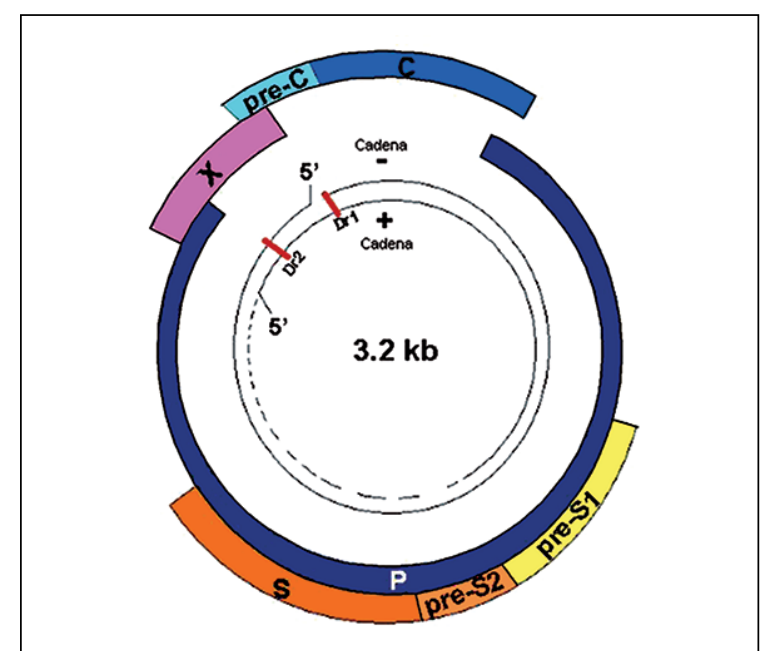

Figura 1. Organización genómica del virus de la hepatitis. Se presentan los 4 marcos abiertos de lectura del genoma del virus de la hepatitis $B$ con sus respectivas regiones.

a la región antigénica altamente conservada, presente en las tres formas del HBsAg, denominada determinante “ $a$ ". La designación $d / y$ es mutuamente excluyente y hace referencia al aminoácido lisina $(\mathrm{Y})$ o $\operatorname{arginina}(\mathrm{R})$ en la posición 122 del HBsAg; las letras $w / r$ también son mutuamente excluyentes y corresponden al aminoácido $Y$ o R en la posición 160 del HBsAg. La designación w1-4 obedece a la identidad del aminoácido en la posición 127; prolina (P) $w 1 / 2$, treonina (T) $w 3$ y leucina (L) $w 4$ y el subtipo q- corresponde a los aminoácidos alanina (A) y glicina $(\mathrm{G})$ en las posiciones 177 y $178^{12,13}$.

La clasificación actual en 10 genotipos (A-J), se basa en la diferencia de la secuencia genómica de 15\%; adicionalmente los subgenotipos presentan una diferencia en la secuencia nucleotídica de $4-8 \%{ }^{12}$.

\section{Vacuna contra el VHB}

La primera vacuna disponible contra el VHB fue derivada de plasma, obtenida de individuos asintomáticos positivos para el HBsAg. Sin embargo, por la dificultad de obtener grandes cantidades de portadores crónicos donantes de plasma y por el riesgo de transmisión del VIH y de otros agentes patógenos, se implementó la producción de vacunas contra el VHB de segunda generación utilizando la tecnología del $\mathrm{ADN}$ recombinante ${ }^{14}$.

Las tres formas del HBsAg del VHB fueron inicialmente producidas en Escherichia coli, pero fue difícil purificarlas en su forma nativa. Posteriormente, la expresión de fragmentos clonados de ADN del VHB codificando la forma $\mathrm{S}$ del $\mathrm{HBsAg}$, primero en células LTK $^{-}$y luego en levaduras, generaron exitosamente las tres formas nativas del HBsAg. Actualmente las vacunas recombinantes contra el VHB se producen en levaduras o la línea celular $\mathrm{CHO}$; estas vacunas contienen las formas $\mathrm{S}$ y $\mathrm{M}$ del HBsAg, tanto en su forma glicosilada como no glicosilada ${ }^{14-15}$.

La vacuna recombinante contra el VHB confiere protección en más de $95 \%$ de los individuos vacunados; sin embargo, ciertos individuos no desarrollan respuesta inmune protectora luego de recibir la vacuna ${ }^{16}$.

La respuesta inmune a la vacuna contra el VHB está relacionada con la inducción de anticuerpos anti-HBs y el desarrollo de células T de memoria. Títulos de anti-HBs de $10 \mathrm{mUI} / \mathrm{mL}$ medidos entre los primeros tres meses después de la administración de la última dosis, es considerado un marcador de protección contra la infección por el $\mathrm{VHB}^{14-16}$.

El primer programa universal de vacunación a escala nacional contra el VHB en niños, se desarrolló en Taiwán en julio de 1984, con un esquema de cuatro dosis de vacuna derivada de plasma (0, 1, 2 y 12 meses de edad). En 1992 se modificó el esquema de la siguiente manera: 0, 1 y 6 meses de edad. Algunos estudios permitieron demostrar una disminución en la seroprevalencia de HBsAg de 10 a $0,6 \%$ en niños bajo 15 años de edad durante las pasadas dos décadas; la incidencia de carcinoma hepatocelular también tuvo una reducción de 0,7/100.000 en 1984 a $0,16 / 100.000$ en 2004. Actualmente la tasa de cobertura de vacunación contra el VHB en Taiwán supera el $97 \%{ }^{17}$.

En Colombia, por la alta incidencia de infección por el VHB en el Departamento del Amazonas, ésta fue la primera región en que se dio inicio al programa universal de vacunación contra este virus. Inicialmente la vacuna contra el VHB se administró en forma monovalente; posteriormente con el advenimiento de las vacunas combinadas y con las grandes ventajas que éstas presentan como ampliación en la cobertura de vacunación, se desarrolló una vacuna pentavalente. Se trata de una vacuna que además confiere protección contra las toxinas de Corynebacterium diphtheriae y Clostridium tetani, antígenos de Bordetella pertussis, y polisacárido de Haemophilus influenzae tipo $\mathrm{b}^{18-19}$.

En 1992, niños entre 0 y 5 años de edad recibieron vacuna recombinante monovalente con un esquema a los 0, 1 y 2 meses. En el año 2001 se introdujo la vacuna pentavalente en este departamento, que se administra a los 2, 4 y 6 meses, después de una dosis de la vacuna monovalente al nacimiento. De la Hoz y cols., en los años 2005 y 2008 , demostraron una reducción de $75 \%$ en la prevalencia de infección por VHB en el Departamento del Amazonas, gracias al programa de vacunación ${ }^{20-22}$.

\section{Estructura del HBsAg}

El HBsAg es una proteína de envoltura de membrana con cuatro dominios transmembrana y una región prin- 
cipal hidrofílica que está expuesta en la superficie de la partícula viral ${ }^{23-24}$.

Los dominios más importantes del HBsAg son: el sitio de unión al receptor del hepatocito, aminoácidos 21-47 de la forma L, que además es esencial para el ensamble y salida de los viriones ${ }^{25-27}$; el dominio ubicado entre los residuos 29-79 que forma el principal "loop" citoplasmático y mediante el cual interactúa con $\mathrm{HBcAg}$; el dominio entre los aminoácidos 3-16 en la forma $\mathrm{M}$, que se une al sitio de polimerización de la albumina, y la principal región hidrofílica, localizada entre los residuos 101-169 de la forma $\mathrm{S}$, que incluye el determinante " $a$ " (aminoácidos 124-147), el cual adquiere su conformación debido a dos puentes disulfuro ${ }^{28-29}$.

El determinante " $a$ " es la región con mayor homología del HBsAg y está definido por una conformación especifica de dos "loops"; el primero conformado por los aminoácidos 124-137 y el segundo por los aminoácidos 139-147; en este último loop se ha encontrado la mutación más común y mejor caracterizada en este dominio del HBsAg, el cambio glicina por arginina en la posición 145 $(\mathrm{G} 145 \mathrm{R})^{30-31}$. También se han descrito mutaciones en los residuos 126, 129, 133, 141 y 144 que evitan el reconocimiento del antígeno a pesar de la respuesta humoral en individuos vacunados ${ }^{32-34}$.

\section{Mutaciones del HBsAg}

Como se mencionó anteriormente, la polimerasa del VHB no posee actividad exo-nucleasa 3'-5'; por tal motivo la replicación de VHB se caracteriza por la generación de poblaciones de virus conocidas como cuasiespecies por acumulación de mutaciones al azar en diferentes regiones del genoma viral ${ }^{35-36}$.

Las cuasiespecies se originan de forma natural durante el curso de la infección por el VHB y si conservan la capacidad de replicación del virus son seleccionadas positivamente y se establecen en la naturaleza ${ }^{35-36}$.

La región $\mathrm{S}$ del ORF S es una de las más conservadas, mientras que las regiones PreS1 y PreS2 (PreS) son las más variables del genoma del VHB. La proteína codificada por la región PreS es considerada altamente inmunogénica, capaz de inducir protección contra el VHB; esta región incluye cinco epítopes $\mathrm{B}^{37}$. No obstante, las mutaciones puntuales en estas regiones no son consideradas de gran relevancia clínica ni epidemiológica en la infección por VHB, como sí lo son las deleciones de fragmentos de PreS. Las deleciones de secuencias que codifican los dominios de unión al hepatocito, de unión a la nucleocapside, de unión al sitio de polimerización de la albumina y las más importantes de todas, deleciones que incluyen la región del promotor de $\mathrm{S}$, están muy relacionadas con la acumulación del HBsAg en el retículo endoplásmico, la generación de estrés oxídativo y el ulterior desarrollo de carcinoma hepato-celular ${ }^{28,38-39}$.

La región $\mathrm{S}$ es la región más conservada del ORF $\mathrm{S}$ del VHB; las mutaciones en esta región tienen mucha relevancia en la antigenicidad de la proteína, ya que en ésta se encuentran los epítopes B y T. La vacuna contra el VHB puede ejercer una presión selectiva sobre mutaciones en el genoma del VHB, principalmente las que se acumulan en la secuencia que codifica el determinante “ $a$ ”. Esta presión selectiva logra que las variantes más aptas que escapan a la vacuna puedan diseminarse en la población inmunizada ${ }^{34}$.

Durante el curso de un programa de inmunización en Italia en niños nacidos de madres HBsAg positivas, algunos niños desarrollaron infección por VHB a pesar de haber sido vacunados. El análisis molecular de los aislados reveló que uno de estos niños fue infectado con una cepa del VHB mutante; este fue el primer caso de variantes de escape reportado y la mutación fue un cambio puntual guanina por alanina ( $\mathrm{G}$ a $\mathrm{A}$ ) en el nucleótido 587, que se traduce en el cambio de aminoácido G145R del HBsAg en su forma pequeña; esta mutación altera la estructura y evita que el HBsAg sea reconocido por los anticuerpos neutralizantes ${ }^{30,40-41}$. Sustituciones puntuales de aminoácidos en esta y otras posiciones del determinante " $a$ " o en secuencias cercanas que impiden el reconocimiento del HBsAg han sido reportadas en individuos vacunados alrededor del mundo ${ }^{40-42}$.

Las mutaciones más importantes reportadas en la región $\mathrm{S}$, se ubican en el determinante " $a$ " o en regiones que flanquean el determinante; sin embargo, existen estudios que han reportado mutaciones en regiones distantes que influyen en el diagnóstico de la infección por el VHB (Tabla 1$)^{23,42}$.

Adicionalmente, Ito y cols., demostraron in vitro una disminución en la eficiencia de secreción, tanto de las partículas subvirales, como de los viriones de aislados de VHB que presentaban mutaciones en secuencias cercanas a la que codifica el determinante "a" tales como I110M, G119E y R169P. En este mismo trabajo también se observó que la mutación M133T restauraba la eficiencia de secreción, debido a que se crea un nuevo sitio de glicosilación en el aminoácido 133. Los resultados de este estudio indican que mutaciones en la secuencia que codifica el determinante " $a$ ", principalmente en el sitio de glicosilación N146 y en regiones cercanas a éste pueden actuar como variantes de escape disminuyendo la capacidad de secreción de los $\mathrm{HBsAg}^{24}$.

Aunque la mayoría de las mutaciones en el HBsAg son silenciosas, es decir, no producen cambio de aminoácidos, mutaciones no sinónimas en la región que codifica el epítope inmunodominante pueden llevar a la propagación del VHB en personas vacunadas y convertirse en un grave problema de salud pública. 


\section{Variantes de escape del VHB}

Las variantes de escape son mutaciones no sinónimas en la secuencia que codifica para el determinante " $a$ " del HBsAg que generan cambio de aminoácido en la proteína; estas mutaciones han sido identificadas en individuos con infección por el VHB a pesar de la presencia de anti-HBs originados en respuesta a la vacuna. Estas variantes pueden no ser reconocidas por pruebas convencionales de ELISA para detectar HBsAg. A partir del descubrimiento de la mutación G145R en Italia en un aislado del VHB proveniente de un niño vacunado, se han realizado estudios en poblaciones de Taiwán, Hungría, Estados Unidos de América (E.U.A.), España y Marruecos para identificar variantes de escape, principalmente en población infantil vacunada y sus madres, con el propósito de caracterizarlas e implementar nuevas medidas de control ${ }^{16,32,43}$.

En los estudios realizados en Taiwán se identificaron variantes de escape con aislados de VHB provenientes de niños vacunados, hijos de madres HBsAg positivas. En 1984, antes de la introducción de la vacuna contra el VHB derivada de plasma, se evaluó una cohorte de 1.200 niños; la frecuencia de mutaciones en la región que codifica el determinante " $a$ " del VHB fue de 7,8\%. Para 1989, primer estudio después del inicio del programa de vacunación, la frecuencia fue de $19,6 \%$; posteriormente se realizaron estudios de detección de variantes de escape cada 5 años, con un aumento considerable de la frecuencia año tras año (Tabla 2). La población de estudio de los trabajos realizados en Taiwán incluyó niños vacunados de diferentes jardines, escuelas y colegios del país. Las mutaciones
Tabla 1. Mutaciones más importantes reportadas en el ORF S (región S) del genoma del virus de hepatitis B

\begin{tabular}{|c|c|c|}
\hline $\begin{array}{l}\text { Posición } \\
\text { Secuencia del ORF S del VHB }\end{array}$ & Aminoácido wild type & Aminoácido mutado \\
\hline 47 & Treonina $(T)$ & Lisina (K) \\
\hline 55 & Serina $(S)$ & Cisteina(C) \\
\hline 59 & Asparagina $(\mathrm{N})$ & Serina $(S)$ \\
\hline 62 & Prolina (P) & Leucina $(L)$ \\
\hline 65 & Cisteina (C) & Serina $(S)$ \\
\hline 80 & Fenilalanina (F) & Leucina (L) \\
\hline 82 & Isoleucina (I) & Leucina (L) \\
\hline 83 & Fenilalanina (F) & Cisteina (C) \\
\hline 85 & Fenilalanina (F) & Cisteina $(C)$ \\
\hline 87 & Leucina $(L)$ & Metionina (M) \\
\hline 89 & Leucina (L) & Isoleucina (I) \\
\hline 110 & Isoleucina (I) & Leucina (L) \\
\hline 112 & Glicina (G) & Arginina (R) \\
\hline 117 & Serina $(S)$ & Isoleucina (I) \\
\hline 159 & Glicina (G) & Arginina (R) \\
\hline 165 & Triftofano (W) & Leucina (L) \\
\hline 184 & Valina (V) & Alanina (A) \\
\hline 186 & Leucina (L) & Arginina (R) \\
\hline 189 & Treonina ( $\mathrm{T}$ ) & Leucina (L) \\
\hline 190 & Valina (V) & Glicina $(G)$ \\
\hline 191 & Triftofano (W) & Alanina (A) \\
\hline 192 & Leucina $(L)$ & Tirosina $(Y)$ \\
\hline 193 & Serina $(S)$ & Asparagina (N) \\
\hline
\end{tabular}

Tabla 2. Variantes de escape del virus de hepatitis B identificadas en estudios en población infantil de Taiwán

\begin{tabular}{|c|c|c|c|c|c|}
\hline Población de estudio & 1984 & 1989 & $\begin{array}{c}\text { Año } \\
1994\end{array}$ & 1999 & 2004 \\
\hline Muestras analizadas marcadores de VHB & 1.200 & 1.134 & 1.515 & 1.357 & 7.234 \\
\hline Muestras analizadas para ADN-VHB en suero & 148 & 91 & 65 & 71 & 94 \\
\hline Muestras seropositivas para ADN-VHB & 103 & 51 & 32 & 13 & 31 \\
\hline Muestras con mutaciones en determinante "a" & $8 / 103(7,8 \%)$ & $10 / 51(19,6 \%)$ & $9 / 32(28,1 \%)$ & $3 / 13(23,1 \%)$ & $7 / 31(22,6 \%)$ \\
\hline \multirow[t]{9}{*}{ Variantes de escape identificadas en determinante "a" } & T126A M133L & T126A & T125A & T131I & T126A \\
\hline & F134L C138S & P127T & $\mathrm{P} 120 \mathrm{Q}+\mathrm{P} 127 \mathrm{~T}$ & G145R & M133L \\
\hline & T140R & Q129H & $\mathrm{T} 126 \mathrm{~A}+\mathrm{T} 143 \mathrm{M}$ & & $\mathrm{F} 134 \mathrm{~L}+\mathrm{T} 148 \mathrm{~A}$ \\
\hline & $\mathrm{T} 140 \mathrm{I}$ & S143W & $\mathrm{T} 126 \mathrm{~S}+\mathrm{D} 144 \mathrm{H}$ & & G145R \\
\hline & T143M & G145R & $\mathrm{D} 144 \mathrm{H}+\mathrm{G} 145 \mathrm{R}$ & & G145A \\
\hline & D144A & G145R W156L & $\mathrm{T} 140 \mathrm{P}$ & & W156C \\
\hline & & & N146S & & \\
\hline & & & T148I & & \\
\hline & & & $C 147 R+C 149 R$ & & \\
\hline
\end{tabular}


identificadas en los niños infectados se presentaron más frecuentemente en la secuencia que codifica el segundo loop inmunodominante del determinante “ $\boldsymbol{a}$ ” del HBsAg, específicamente los aminoácidos 140-149; la mutación G145R fue la más frecuente ${ }^{44-47}$.

En un estudio realizado en Hungría en 28 niños anti-HBc y/o HBsAg positivos que recibieron vacuna recombinante al nacimiento y en 40 mujeres embarazadas anti-HBc positivas, de las cuales no se conocía el estado de vacunación, se reportó una frecuencia de mutaciones de $41,6 \%$ para el primer grupo y $52,6 \%$ para el segundo; dentro de estas mutaciones no se encontró G145R. La más frecuente en este estudio fue prolina por treonina en la posición $127(\mathrm{P} 127 \mathrm{~T})^{48}$.

Además de las dos mutaciones de escape dominantes en el determinante " $a$ " G145R y P127T, muchas otras mutaciones han sido reportadas dentro de esta región y cerca a ella; de éstas, las más frecuentes son C121S, C124Y, C137W/Y C147Y/R, T115N y Y134H. En ensayos de ELISA con HBsAg recombinantes con estas mutaciones se ha demostrado la disminución de la avidez para unirse a anti-HBs. Los cambios de cisteínas por otros aminoácidos producen una alteración del epítope conformacional del determinante " $a$ " del HBsAg, pues estas cisteínas son las encargadas de formar los dos puentes disulfuros, indispensables para la formación de los dos loops inmuno-dominantes ${ }^{24,45-47}$.

En pacientes con infeccion crónica tambien se han detectado variantes de escape, las cuales pueden estar relacionadas con persistencia viral y gravedad de la enfermedad hepática. En un estudio realizado en Marruecos, en individuos con infección crónica por el VHB se identificaron las mutaciones de escape L109Q, P120T, T126A, Q129H, G130A, T131I y D144A ${ }^{49}$. Considerando que en los individuos asintomáticos con infección crónica el VHB puede permanecer por décadas, éstos se convierten en un reservorio importante del virus y la selección de las mutantes de escape en estos pacientes puede incrementar el problema de transmisión en la población general, conviertiendose en un riesgo para la salud pública.

Un estudio realizado en E.U.A., en muestras de suero de niños nacidos de madres positivas para el HBsAg, demostró que 94 de 1092 (8,6\%) niños, fueron positivos para este marcador, pese a haber recibido la vacuna pentavalente. El ADN viral proveniente de muestras de suero de $22(23,4 \%)$ de estos niños, presentó mutaciones en la secuencia del determinante “ $\boldsymbol{a}$ ” del HBsAg, la mayoría entre los aminoácidos 142-145; las mutaciones más frecuentes en este estudio fueron P142S, D144A y G145R, aparte de las poco comunes K141E y C149R ${ }^{50}$.

Un estudio similar fue realizado en Tailandia, en una cohorte de 517 niños con el esquema completo de vacunación, nacidos de madres infectadas con el VHB; 14 de estos niños progresaron a infección crónica después de seis meses. Un estudio pareado entre madres y niños infectados demostró que dos de los 14 niños presentaron aislados con las mutaciones D144G y G145K, las cuales no estuvieron presentes en las muestras provenientes de sus madres; este resultado sugiere que las mutantes pudieron emerger y haber sido seleccionadas debido a la presión inmune durante la infección de los niños y no se transmitieron en forma vertical. La frecuencia de variantes de escape en este estudio en niños infectados por el VHB y vacunados fue de 14\%, la cual es considerada como alta ${ }^{51}$.

En Colombia, recientemente se realizó un estudio con 1.275 niños vacunados y sus 571 madres pertenecientes a comunidades indígenas del Departamento del Amazonas. En este estudio se identificaron dos variantes de escape en $2 / 7$ (28,5\%) de las muestras; la mutación W156* se caracterizó en una muestra de un niño con infección oculta por VHB y la mutación G145R en una muestra de una madre. Este es el primer reporte de la circulación de variantes de escape del VHB en Latinoamérica (Información no publicada $)^{52}$.

Debido al traslape o superposición de los ORF P y $\mathrm{S}$ en el genoma del VHB, las mutaciones asociadas con resistencia a antivirales frecuentemente también están asociadas con cambios en el HBsAg, en el dominio de unión de anticuerpos neutralizantes, específicamente en los aminoácidos cercanos al determinante “ $\boldsymbol{a}$ ” del HBsAg. Las principales mutaciones reportadas en el ORF P que afectan el HBsAg son la rtM204V/I, la cual confiere resistencia a lamivudina y también reduce la eficiencia de replicación del VHB in vitro, y la rtL180M que restaura el "fitness" viral (habilidad relativa de una población viral para producir progenie infecciosa bajo un conjunto de condiciones ambientales definidas); esta mutación también aumenta la resistencia a lamivudina in vitro. Otra mutación importante es la rtV173L; es una mutación compensatoria que es seleccionada en pacientes resistentes a lamivudina y potencia la replicación viral. Por medio de modelación computarizada se ha mostrado que en el proceso de replicación viral el residuo rtV173 se localiza cerca del molde de ARN, cerca al sitio activo de la transcriptasa reversa; la sustitución de valina por leucina en este residuo potencia la polimerización del $\mathrm{ADN}$ por reposicionamiento de la cadena molde afectando otros aminoácidos importantes en el proceso de polimerización ${ }^{53-54}$.

El acrónimo PMEADAVs (potenciales mutantes de escape asociadas con antivirales) corresponde a las mutaciones que ocurren en el ORF P y que igualmente resultan en cambios en el ORF S. Estas mutaciones se producen debido al tratamiento antiviral con análogos de nucleósidos, como lamivudina, telbivudina y entecavir y de nucleótidos como adefovir y tenofovir. Las PMEADAVs más reportadas son: rtM204V/sI195M, 
rtM204I/sW196S, rtM204I/sW196L, rtV173L/sE164D, rtA181T/sW172*, codón de parada, rtA181T/sW172L, y rtA181V/sL173F. Estas mutaciones son características en pacientes con infección por hepatitis B crónica y se dan tanto en inmunizados como no inmunizados ${ }^{55-56}$. Se ha reportado que la triple mutación $\mathrm{rtV} 173 \mathrm{~L} / \mathrm{sE} 164 \mathrm{D}$, rtL180M, rtM204V/sI195M reduce la unión del HBsAg a los anti-HBs en un nivel similar a la mutación dominante G145R (Figura 2) ) $^{56-57}$.

Hasta el momento ha sido extensa la investigación realizada con el objetivo de identificar y caracterizar las variantes de escape del VHB que se generan, tanto en individuos vacunados como no vacunados, considerándose así la aparición de estas mutaciones como uno de los principales mecanismos de evasión a la inmunoprofilaxis contra el VHB. Sin embargo, son necesarios estudios adicionales para evaluar el perfil epidemiológico y el significado biológico y clínico que estas variantes puedan tener en los individuos inmunizados contra el VHB.

\section{Importancia epidemiológica de las mutantes de escape}

Actualmente existe consenso que las cepas del VHB con mutaciones en el ORF $\mathrm{S}$ pueden generar infecciones activas. Por lo tanto, la emergencia y diseminación de estas cepas pueden crear un problema de salud pública de gran importancia. Incluso existen modelos matemáticos que predicen el predominio a nivel global en un período de 60-100 años de la variante de escape G145R, la más estable de cuantas se conocen, sobre las cepas silvestres que circulan en la actualidad, y la sustitución total dentro de aproximadamente 200 años $^{58-59}$.

Dado que la vacunación de la población susceptible es fundamental para el control de la infección por el VHB, la comunidad científica se afana por diseñar nuevos prototipos de vacunas que disipen este problema. En este sentido, incorporar a la vacuna clásica HBsAg recombinantes con las mutaciones más frecuentes o utilizar como antígeno un HBsAg recombinante en el que el primer loop del domino hidrofílico, aminoácidos 121-129 del determinante “ $a$ ”, o la región PreS resulten inmunodominantes, son opciones cuya factibilidad debe ser elucidada en un futuro próximo ${ }^{60}$.

La aparición de virus con las mutaciones anteriormente citadas es un hecho conocido desde hace tiempo; sin embargo, ni la prevalencia en población general ni en portadores crónicos ha sido establecida, por lo que el comportamiento epidemiológico de estas mutantes no se conoce en realidad. Además, la capacidad de detección de los kits comerciales de uso común para detectar el HBsAg es variable y se requieren estudios comparativos amplios con mutantes recombinantes ${ }^{60-61}$.

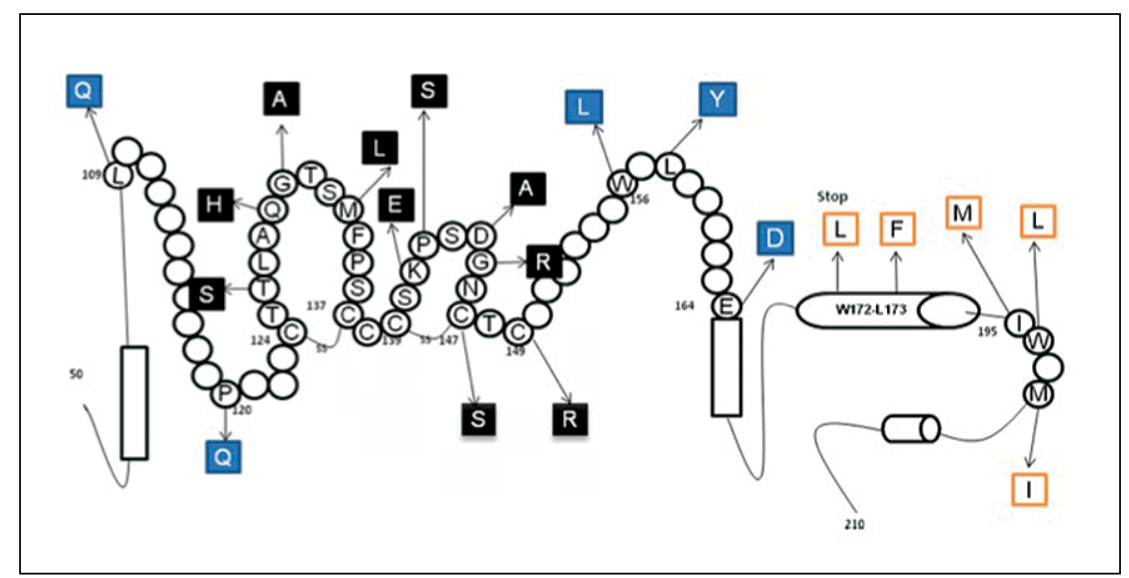

Figura 2. Mutaciones más frecuentes en la principal región hidrofílica del antígeno de superficie del virus de la hepatitis B. En cuadro negro se muestran las variantes de escape en el determinante "a" asociadas a vacunación; en cuadro azul las variantes de escape fuera del determinante "a" y en cuadro naranja las mutaciones asociadas a resistencia antiviral en la región del ORF S que sobrelapa con el dominio catalítico de la polimerasa. Adaptado de 24, 55-57.

\section{Conclusión}

La aparición de variantes de escape en la secuencia que codifica el determinante " $a$ " del HBsAg o en regiones cercanas ha tenido importantes implicaciones para la salud pública mundial; estas mutaciones están relacionadas con la infección oculta por VHB, reactivación del VHB, falla en la detección del HBsAg por las pruebas diagnósticas, reinfección en pacientes receptores de trasplante de hígado y se ha reportado que pueden infectar individuos inmunizados, puesto que los anticuerpos inducidos por la vacuna no las neutralizan. Adicionalmente son mutantes estables y pueden ser transmitidas de manera horizontal $\mathrm{y}$ vertical en poblaciones vacunadas y no vacunadas.

Estas mutaciones han sido reportadas en países de alta prevalencia para la infección por VHB como Taiwán. Este país es el que tiene el mejor registro de identificación de variantes de escape; a partir del inicio del programa universal de vacunación, cada cinco años se han realizado estudios para evaluar la eficacia de la vacuna y la frecuencia en la aparición de variantes de escape. Pero en países de intermedia y baja prevalencia para la infección por VHB también han sido identificadas estas variantes de escape, como lo demuestran los estudios realizados en Italia, España, Hungría, E.U.A., y recientemente en Colombia.

También con modelos matemáticos se ha demostrado que estas variantes, principalmente la más frecuente de todas, G145R, reemplazara a las cepas wild type en un período no mayor a 200 años. Esto es alarmante porque esta mutación ha sido identificada en individuos que presentan el esquema completo de vacunación para el VHB y aun así son infectados por el virus, haciendo necesaria la 
investigación y el trabajo en la implementación de nuevas vacunas que contengan epitopes distintos al determinante "a", en las regiones PreS1, Pres 2 y S del ORF S del VHB, además de terapias dirigidas contra estas variantes.

\section{Resumen}

La infección por el virus de la hepatitis B (VHB) es un problema de salud pública global. Considerando la morbi-mortalidad por VHB y las pérdidas económicas que causa esta infección, se han implementado políticas y medidas para el control, principalmente en regiones donde la infección por este virus es endémica, con altas tasas de infección vertical y horizontal. Una de esas medidas corresponde al desarrollo de la vacuna recombinante. El 92\% de los países en el mundo ha implementado esta vacuna con una cobertura global de $69 \%$. Las variantes de escape del VHB corresponden a aislados del virus que presentan mutaciones en la secuencia que codifica para el determinante "a"; estas mutaciones generan cambios en la secuencia de aminoácidos del antígeno de superficie HBsAg que evitan la neutralización de las partículas virales por anticuerpos generados en respuesta a la vacuna o la infección. Las variantes de escape pueden infectar individuos vacunados y han sido identificadas en poblaciones de países con diferente patrón epidemiológico.

\section{Referencias bibliográficas}

1.- Elgouhari H, Abu-Rajab Tamimi T, Carey W. Hepatitis B virus infection: understanding its epidemiology, course, and diagnosis. Clev Clin J Med 2008; 75: 881-9.

2.- Franco E, Bagnato B, Marino M, Meleleo C, Serino L, Zaratti L. Hepatitis B: Epidemiology and prevention in developing countries. World $\mathrm{J}$ Hepatol 2012; 2: 74-80.

3.- Idrovo B, Álvarez P. Epidemiología e historia natural de la hepatitis B. Rev Col Gastroenterol 2009; 24: 4-12.

4.- Parana R, Almeida D. HBV epidemiology in Latin America. J Clin Virol 2005; 34: 130-3.

5.- Shepard C, Simard E, Finelli L, Fiore A, Bell B. Hepatitis B virus infection: epidemiology and vaccination. Epidemiol Rev 2006; 28: 112-25.

6.- Jinlin H, Zhihua L, Fan G. Epidemiology and prevention of hepatitis $B$ virus infection. Int $J$ Med Sci 20052 (1): 50-7.

7.- Pawlotsky J. The concept of hepatitis B virus mutant escape. J Clin Virol 2005; 34: 125-9.

8.- Liang T, Hepatitis B: the virus and disease. Hepatology 2009; 49: 13-21.

9.- Beck J, Nassal M. Reconstitution of a functional duck hepatitis B virus replication initiation complex from separate reverse transcriptase domains expressed in Escherichia coli. J Virol 2001; 75: 7410-9.

10.- Kidd-Ljunggren K, Miyakawa Y, Kidd A. Genetic variability in hepatitis B viruses. J Gen Virol 2002; 83: 1267-80.

11.- Weber B. Genetic variability of the S gene of hepatitis B virus: clinical and diagnostic impact. J Clin Virol 2005; 32: 102-12.

12.- Norder H, Couroucé A, Magnius L. Molecular basis of hepatitis $\mathrm{B}$ virus serotype variations within the four major subtypes. J Gen Virol 1992; 73: 3141-5.

13.- Wong V, Sung J. Diagnosis and personalized management of hepatitis B including significance of genotypes. Curr Opin Infect Dis 2012; 25: 570-7.

14.- Michel M, Tiollais P. Hepatitis B vaccines: protective efficacy and therapeutic potential. Pathol Biol 2010; 58: 288-95.

15.- Huang L, Lu C, Chen D. Hepatitis B virus infection, its sequelae, and prevention by vaccination. Curr Opin Immunol 2011; 23: $237-43$.

16.- Somi M, Hajipour B. Improving hepatitis B vaccine efficacy in end-stage renal diseases patients and role of adjuvants. ISRN Gastroenterol 2012; 2012: 9604-13.

17.- Ni Y, Chen D. Hepatitis B vaccination in children: the Taiwan experience. Pathol Biol 2010; 58: 296-300.

18.- Sharma H, Yadav S, Lalwani S, Kapre S, Jadhav S, Chakravarty A, et al. Immunogenicity and safety of an indigenously manufactured reconstituted pentavalent (DTwP-HBV+Hib) vaccine in comparison with a foreign competitor following primary and booster immunization in Indian children. Hum Vaccin 2011; 7: 451-7.

19.- Hla K, Thein S, Aye A, Han H, Bock H, David $\mathrm{M}$, et al. Reactogenicity and immunogenicity profiles of a novel pentavalent diphtheriatetanus-whole cell pertussis-hepatitis B and Haemophilus influenzae type B vaccine: a randomized dose-ranging trial of the Hib tetanus-conjugate content. Pediatr Infect Dis J 2006; 25: 706-12.

20.- de la Hoz F, Gamarram A, Velandia M, Rojas M. Factores de riesgo en la transmisión de la hepatitis B en la amazonía colombiana. Biomedica 1992; 12: 5-9.

21.- de la Hoz F, Pérez L, de Neira M, Hall A. Eight years of hepatitis $\mathrm{B}$ vaccination in Colombia with a recombinant vaccine: factors influencing hepatitis B virus infection and effectiveness. Int J Infect Dis 2008; 12: 183-9.

22.- de la Hoz F, Pérez L, Wheeler J, de Neira M,
Hall A. Vaccine coverage with hepatitis B and other vaccines in the Colombian Amazon: do health worker knowledge and perception influence coverage? Trop Med Int Health 2005; 10: $322-9$.

23.- Hsu H, Chang M, Liaw S, Ni Y, Chen H. Changes of hepatitis B surface antigen variants in carrier children before and after universal vaccination in Taiwan. Hepatology 1999; 30: 1312-7.

24.- Ito K, Qin Y, Guarnieri M, García T, Kwei K, Mizokami M, et al. Impairment of hepatitis $B$ virus virion secretion by single-amino-acid substitutions in the small envelope protein and rescue by a novel glycosylation site. J Virol 2010; 84: 12850-61.

25.- Gao Z, Li T, Wang J, Du J, Li Y, Li J, et al. Mutations in preS genes of genotype $\mathrm{C}$ hepatitis $B$ virus in patients with chronic hepatitis $B$ and hepatocellular carcinoma. J Gastroenterol 2007; 42: 761-8

26.- Patient R, Hourioux C, Sizaret P, Trassard S, Sureau C, Roingeard P. Hepatitis B virus subviral envelope particle morphogenesis and intracellular trafficking. J Virol 2007; 81: 3842-51.

27.- Barrera A, Guerra B, Notvall L, Lanford R. Mapping of the hepatitis B virus pre-S1 domain involved in receptor recognition. J Virol 2005; 79: 9786-98.

28.- Khan N, Guarnieri M, Ahn S, Li J, Zhou Y, Bang G, et al. Modulation of hepatitis B virus secretion by naturally occurring mutations in the S gene. J Virol 2004; 78: 3262-70.

29.- Lin C, Wang G, Jow G, Chen B. Functional analysis of hepatitis B virus pre-s deletion variants associated with hepatocellular carcinoma. J Biomed Sci 2012; 19: 1-10.

30.- Carman W, Zanetti A, Karayiannis P, Waters J, Manzillo G, Tanzi E, et al. Vaccine-induced escape mutant of hepatitis B virus. Lancet 1990; 336: 325-9. 
31.- Amini-Bavil-Olyaee S, Vucur M, Luedde T, Trautwein C, Tacke F. Differential impact of immune escape mutations G145R and P120T on the replication of lamivudine-resistant hepatitis $B$ virus e antigen-positive and -negative strains. J Virol 2010; 84: 1026-33.

32.- Alcaraz M. Virus de la hepatitis B: estructura genómica y marcadores clínicos. Control Calidad SEIMC2000.Disponible en: http://www. seimc.org/contenidos/ccs/revisionestematicas/ serologia/Rvirhbs.pdf. Octubre 2013.

33.- Ijaz S, Ferns R, Tedder R. A 'first loop' linear epitope accessible on native hepatitis B surface antigen that persists in the face of 'second loop' immune escape. J Gen Virol 2003; 84: 269-75.

34.- Hunt C M, McGill J M, Allen M I, Condreay L D. Clinical relevance of hepatitis B viral mutations. Hepatology 2000; 31: 1037-44.

35.- Park S, Kim Y, Park E, Ryu H, Jung G. Fidelity of hepatitis B virus polymerase. Eur J Biochem 2003; 270: 2929-36.

36.- Beck J, Nassal M. Hepatitis B virus replication. World J Gastroenterol 2007; 13: 48-64.

37.- Naaz A, Shakoori A. The cloning of PreS gene from Pakistanian isolates of hepatitis B virus into a high expression vector pKK223-3. Pakistan J Zool 2005; 37: 165-8.

38.- Chen Y, Qian F, Yuan Q, Li X, Wu W, Guo X, et al. Mutations in hepatitis B virus DNA from patients with coexisting HBsAg and anti-HBs. J Clin Virol 2011; 52: 198-203.

39.- Jang J, Kim H, Kim H, Shin W, Kim K, Lee J, et al. Association of concurrent hepatitis B surface antigen and antibody to hepatitis B surface antigen with hepatocellular carcinoma in chronic hepatitis B virus infection. J Med Virol 2009; 81: 1531-8.

40.- Weinberger K, Bauer T, Böhm S, Jilg W. High genetic variability of the group-specific a-determinant of hepatitis $B$ virus surface antigen (HBsAg) and the corresponding fragment of the viral polymerase in chronic virus carriers lacking detectable $\mathrm{HBsAg}$ in serum. J Gen Virol 2000; 81: 1165-74.

41.- Mateos M, Casado J, Moreira B. Hepatitis crónica B por mutante G145R del virus de la hepatitis B. Med Clin 2006; 127: 596-7.

42.- Moradi A, Zhand S, Ghaemi A, Javid N, Tabarraei A. Mutations in the $\mathrm{S}$ gene region of hepatitis B virus genotype D in Golestan Province-Iran. Virus Genes 2012; 44: 382-7.

43.- El Chaar M, Candotti D, Crowther R, Allain J. Impact of hepatitis B virus surface protein mutations on the diagnosis of occult hepatitis B virus infection. Hepatology 2010; 52: 1600-10.

44.- Chang M. Impact of hepatitis B vaccination on hepatitis B disease and nucleic acid testing in high-prevalence populations. J Clin Virol 2006; 36: 45-50.

45.- Hsu H, Chang M, Ni Y, Chen H. Survey of hepatitis B surface variant infection in children 15 years after a nationwide vaccination programme in Taiwan. Gut 2004; 53: 1499-503.

46.- Hsu H, Chang M, Ni Y, Chiang C, Chen H, $\mathrm{Wu} \mathrm{J}$, et al. No increase in prevalence of hepatitis B surface antigen mutant in a population of children and adolescents who were fully covered. J Infect Dis 2010; 201(8): 1192-200.

47.- Chen C, Hsu H, Liu C, Chang M, Ni Y. Stable seroepidemiology of hepatitis B after universal immunization in Taiwan: A 3-year study of national surveillance of primary school students. Vaccine 2010; 28: 5605-8.

48.- Szomor K, Denes A, Garai E, Rusvai E, Berencsi G, Takacs M. Mutation spectra of the surface-protein-coding region of the HBV genome in $\mathrm{HBV}$-vaccinated and non-vaccinated individuals in Hungary. Arch Virol 2008; 153 : 1885-92.

49.- Kitab B, El Feydi A, Afifi R, Derdabi O, Cherradi Y, Benazzouz M, et al. Hepatitis B genotypes/subgenotypes and MHR variants among Moroccan chronic carriers. J Infect 2011; 63: 66-75.

50.- Zuckerman J, Zuckerman A. Mutations of the surface protein of hepatitis B virus. Antivir Res 2003; 60: 75-8.

51.- Sa-Nguanmoo P, Tangkijvanich P, Tharmaphornpiles P, Rasdjarmrearnsook A, Plianpanich S, Thawornsuk N, et al. Molecular analysis of hepatitis B virus associated with vaccine failure in infants and mothers: a case-control study in Thailand. J Med Virol 2012; 84: 1177-85.

52.- Jaramillo, C. Genotipificación de aislados e identificación de variantes de escape del virus de la hepatitis B (VHB) provenientes de individuos de comunidades indígenas del Departamento del Amazonas, Colombia. 2013. Tesis Maestría (Información no publicada).

53.- Delaney W, Yang H, Westland C, Das K, Arnold E, Gibbs C, et al., The hepatitis B virus polymerase mutation $\mathrm{rtV} 173 \mathrm{~L}$ is selected during lamivudine therapy and enhances viral replication in vitro. J Virol 2003; 77: 11833-41.

54.- Lu H, Zeng Z, Xu X, Zhang N, Yu M, Gong W. Mutations in surface and polymerase gene of chronic hepatitis B patients with coexisting HBsAg and anti-HBs. World J Gastroenterol 2006; 12: 4219-23.

55.- Sayan M, Akhan, S. Antiviral drug-associated potential vaccine-escape hepatitis B virus mutants in Turkish patients with chronic hepatitis B. Int J Infect Dis 2011; 15: 722-6.

56.- Sheldon J, Ramos B, García-Samaniego J, Ríos P, Bartholomeusz A, Romero M, et al. Selection of hepatitis B virus (HBV) vaccine escape mutants in HBV-infected and HBV/HIVcoinfected patients failing antiretroviral drugs with anti-HBV activity. J Acquir Immune Defic Syndr 2007; 46: 279-82.

57.- Sheldon J, Soriano V. Hepatitis B virus escape mutants induced by antiviral therapy J Antimicrob Chemother 2008; 61: 766-8.

58.- Navarro D, Esparcia, O, Granda, S. Mutantes del virus de la hepatitis B en el gen S. Control calidad SEIMC 2005.Disponible en: https://www.seimc.org/contenidos/ccs/ revisionestematicas/serologia/Mutavhb.pdf. Octubre 2013.

59.- Lai M, Lin T, Tsao K, Huang C, Hsiao M, Liang K. et al. Increased seroprevalence of HBV DNA with mutations in the s gene among individuals greater than 18 years old after complete vaccination. Gastroenterology 2012; 143: 400-7.

60.- Avellon A, Echevarría J. Frequency of hepatitis $B$ virus ' $a$ ' determinant variants in unselected Spanish chronic carriers. J Med Virol 2006; 78: 24-36.

61.- Avellon A, Echevarría J. Frecuencia de variantes del determinante a del virus de la hepatitis B. 2010. http://www.universidaddelasalud.es/pdf/ investigacionysalud/pdf/FRECUENCIA $\% 20$ DE\%20VARIANTES\%20DEL\%20 DETERMINANTE.pdf. Octubre de 2013. 